\title{
Correlation Between Polymorphisms at Interleukin-6 But Not at Interleukin-10 Promoter and the Risk of Human T Lymphotropic Virus Type I-Associated Myelopathy/Tropical Spastic Paraparesis in Brazilian Individuals
}

\author{
Sandra Rocha Gadelha, ${ }^{1,2}$ Luiz Carlos Junior Alcântara, ${ }^{1,2}$ Gisele Calazans Costa, ${ }^{1}$ \\ Angelina Xavier Acosta, ${ }^{1,3}$ Domingos Rios, ${ }^{4}$ Simone Kashima, ${ }^{5}$ Dimas Tadeu Covas, ${ }^{5}$ \\ and Bernardo Galvão-Castro ${ }^{1,2 *}$ \\ ${ }^{1}$ Laboratório Avançado de Saúde Pública/Centro de Pesquisas Gonçalo Moniz/Fundaçáo Oswaldo Cruz, \\ Salvador, Bahia, Brazil \\ ${ }^{2}$ Escola Bahiana de Medicina e Saúde Pública / Fundação para o Desenvolvimento das Ciências, Salvador, Bahia, Brazil \\ ${ }^{3}$ Departamento de Pediatria, Faculdade de Medicina, Universidade Federal da Bahia (UFBA), Bahia, Brazil \\ ${ }^{4}$ Laboratório de Genética Molecular, Departamento de Ciências Biológicas (DCB), \\ Universidade Estadual do Sudoeste da Bahia (UESB), Bahia, Brazil \\ ${ }^{5}$ Hemocentro de Ribeirão Preto, São Paulo, Brazil
}

HTLV-1 is the etiologic agent of ATL and HAM/ TSP. The majority of HTLV-1-infected individuals remain asymptomatic, indicating that the infection alone is not sufficient to cause the diseases. It has been reported that cytokine gene polymorphisms, including polymorphisms at IL-6 and IL-10 gene, might be important. We analyzed SNP in the promoter region of the IL-6: -174 , $-572,-597$, and -634 positions, and IL-10: -592 position to evaluate the role of these polymorphisms in the $\mathrm{HAM} / \mathrm{TSP}$ pathogenesis in 133 HTLV-1 infected individuals and in 100 healthy individuals from Salvador, Bahia, Brazil. The $-634 \mathrm{C}$ allele frequencies were higher among $\mathrm{HAM} / \mathrm{TSP}$ patients $(21.2 \%)$ than among oligosymptomatic $(6.5 \% ; P=0.038)$ and asymptomatic $(9.5 \% ; P=0.025)$ subjects. Similarly, the $-174 \mathrm{G}$ allele frequencies were higher in HAM/ TSP patients than in oligosymptomatic patients $(P=0.02)$. Moreover, the $-634 \mathrm{GC} /-174 \mathrm{GG}$ genotype combination was identified at a higher frequency $(38.5 \%)$ in the HAM/TSP patients than in subjects with other clinical status $18.7 \%$; $P=0.016$ for oligosymptomatic and $15.5 \%$, $P=0.012$ for asymptomatic patients). However, the multivariate logistic regression including the genotypes of the three studied loci showed that only -634 C IL-6 carriers remain as significant and independent TSP/HAM predictor (odds ratio $[\mathrm{OR}]=5.31 ; 95 \%[\mathrm{Cl}]=1.60-17.56 ; P=0.006)$. We suggest that $-634 \mathrm{G} \mathrm{C}$ in IL-6 could contribute to $\mathrm{HAM} / \mathrm{TSP}$ development and that identification of the collective influence of several cytokine polymorphisms, their prevalence, and their interaction could help to better understand this disease. J. Med. Virol. 80:2141-2146, 2008. ๑ 2008 Wiley-Liss, Inc.

KEY WORDS: HTLV-1; interleukin-6; interleukin10; polymorphisms; Brazilian populations

\section{INTRODUCTION}

The human T-cell lymphotropic virus type 1 (HTLV-1) (Family Retroviridae, subfamily Orthovirinae, genus Deltaretrovirus, species Primate T-lymphotropic virus I) is the etiologic agent of adult T-cell leukemia (ATL) and tropical spastic paraparesis/HTLV-1-associated mielopathy (HAM/TSP) [Poiesz et al., 1980; Gessain et al., 1985; Osame et al., 1986]. The majority of HTLV-1infected individuals remain asymptomatic (95-98\%), indicating that the infection alone is not sufficient to cause the diseases [Murphy et al., 1989; Orland et al., 2003]. It has been demonstrated that the Tax protein of HTLV is a transcriptional activator of viral and host cellular genes, including interleukin 2 (IL-2), the $\alpha$ chain of the IL-2 receptor (IL-2R $\alpha$ ), interleukin 6 (IL-6), interleukin 10 (IL-10), c-fos, granulocyte-macrophage

*Correspondence to: Prof. Bernardo Galvão-Castro, MD, PhD, LASP/CPqGM/FIOCRUZ 121, rua Waldemar Falcão, Candeal 40296710 Salvador, BA, Brazil. E-mail: bgalvao@cpqgm.fiocruz.br Accepted 19 August 2008

DOI 10.1002/jmv.21341

Published online in Wiley InterScience

(www.interscience.wiley.com) 
colony stimulating factor, etc [Mori et al., 1996; Li and Gaynor, 2000]. Tax does not bind to DNA directly nor has an enzymatic function; its ability to activate many genes is conferred by its protein-protein interactions with different cellular factors [Li and Gaynor, 2000].

Although few studies have been carried out on the host genetic susceptibility to HAM/TSP [Jeffery et al., 1999; Kodama et al., 2004; Rafatpanah et al., 2004; Saito et al., 2005; Nobuhara et al., 2006], it has been reported that cytokine gene polymorphisms might play a role in the pathogenesis of this disease [Nishimura et al., 2000; Nishimura et al., 2002; Sabouri et al., 2004].

Indeed, previous studies have demonstrated that polymorphism at IL-6 and IL-10 promoter, at position -634 and -592 , respectively, could be involved in the pathogenesis of HAM/TSP [Nishimura et al., 2002; Sabouri et al., 2004]. However, single nucleotide polymorphisms (SNP) and haplotype frequencies, including that at IL-6 and IL-10 promoter, can differ in populations with different ethnic backgrounds [Fishman et al., 1998; Cox et al., 2001; Hoffmann et al., 2002; Meenagh et al., 2002; Plothow et al., 2003]. Recently, we have demonstrated that there is a great heterogeneity in the frequency of $-174 \mathrm{G} / \mathrm{C}$ and $-634 G / C$ IL-6 variants among Brazilian regional subpopulations with different ethnic backgrounds [Gadelha et al., 2005].

IL-6, a pleiotropic cytokine, is synthesized in response to diverse stimuli and SNP in the human IL-6 promoter at $-634,-174$ and -572 positions have been associated to the gene function and disease susceptibility [Fishman et al., 1998; Kitamura et al., 2002; Nishimura et al., 2002; Belluco et al., 2003; Kubaszek et al., 2003]. The $-174 G$ / C IL-6 variant lies immediately upstream of multi-responsive element (MRE). Compared to the $-174 \mathrm{G}$ allele, the $-174 \mathrm{C}$ allele resulted in lower plasma IL-6 levels [Fishman et al., 1998].

IL-10 is produced particularly by $\mathrm{T}$ regulatory cells, but also by $\mathrm{Th}_{0}, \mathrm{Th}_{1}, \mathrm{Th}_{2}$, B-cells and monocytes [Moore et al., 2001; Taylor et al., 2006]. This cytokine is related to antigen-specific T-cell suppression (both $\mathrm{Th}_{1}$ and $\mathrm{Th}_{2}$ ). The polymorphism at -592 position lies between the Sp1 and Ets recognition site and may affect the binding of the transcriptional factor. In fact, the region between -652 and -571 nucleotide is necessary for IL-10 transcription [Ma et al., 2001]. In addition, it has been demonstrated that $-592 \mathrm{~A}$ allele was correlated with in vitro reduced IL-10 production [Rosenwasser and Borish, 1997] and lower HTLV-1 Tax-mediated transcriptional activity [Sabouri et al., 2004].

In this study, we analyzed SNP in the promoter region of the IL-6: $-174,-572,-597$, and -634 positions, and IL-10: -592 position, in order to evaluate the role of these polymorphisms in the HAM/TSP pathogenesis in samples from Salvador, Bahia, the city with the highest prevalence of HTLV-1 infection in Brazil [Galvão-Castro et al., 1997; Dourado et al., 2003].

\section{MATERIALS AND METHODS}

\section{Study Design and Population}

Hundred thirty-three infected individuals (84 HTLV1 asymptomatic carriers, 23 oligosymptomatic, and $26 \mathrm{HAM}$ /TSP patients) recruited from the HTLV reference center located at Bahia School of Medicine and Public Health/Bahia Foundation for Scientific Development (EBMSP) between June 2005 and July 2006, and 100 healthy individuals from the general population of Salvador, Bahia, Brazil [Dourado et al., 2003] were enrolled in this study. The HTLV-1 infection in healthy and infected individuals was assessed according to the algorithm recommended by the Brazilian ministry of health. Briefly, plasma samples repeatedly positive in duplicate by ELISA (HTLV-1/ HTLV-2 Ab-Capture ELISA Test System, Ortho, Clinical Diagnostic Inc., Raritan, NJ) were confirmed and discriminated between HTLV-1 and HTLV-2 using Western blot (HTLV blot 2.4, Genelabs, Singapore). The HAM/TSP patients were classified according to the expanded disability status scale (EDSS) and Osames motor disability score (OMDS). All subjects provided written informed consent. The infected individuals classified as oligosymptomatic were clinically different from HAM/TSP patients. They presented some neurological symptoms, such as disabilities in gait and sphincter control areas, weakness, bladder, and erectile dysfunctions, but they did not fulfill the HAM/TSP criteria. All volunteers gave written informed consent before participating. The study received official institutional and ethical approval of the EBMSP/FBDC ethic committee.

\section{DNA Extraction and Single Nucleotide Polymorphism (SNP) Detection}

Genomic DNA was previously extracted from peripheral blood mononuclear cells by proteinase $\mathrm{K}$ treatment followed by phenol-chloroform method. The analysis of the polymorphisms $-634 G / C$ at IL-6 and $-592 C / A$ at IL-10 were done by PCR amplification followed by restriction fragment length polymorphism (RFLP) using primers and PCR conditions, as previously described [Nishimura et al., 2002; Sabouri et al., 2004]. The amplified products were digested with $B s r B I$ (634G/ C) and $R s a \mathrm{I}$ (-592C/A) restriction endonucleases, and both digested and undigested samples were electrophoresed on $2 \%$ agarose gels followed by Ethidium bromide staining. For determination of $-174 G / C$, $-572 G / C$, and $-597 G / A$ IL-6 polymorphisms, the SNP assay by real-time PCR was done. The SNP assays were purchased from Applied Biosystem (Foster City, $\mathrm{CA}$ ), and they were carried out according to the manufacturer's instructions.

\section{Statistical Methods}

Allele frequencies were estimated by gene counting. The agreement of genotype frequencies with HardyWeinberg expectations and the linkage disequilibrium 
were tested using the Genepop [Raymond and Rousset, 1995]. The heterogeneity of polymorphism frequencies among populations was tested by $\chi^{2}$ test followed by adjusted $\chi^{2}$ residual analysis or with Fisher's exact test using the PEPI package, version 4.0 [Abramson and Gahlinger, 2001]. A $P$-value $<0.05$ was considered statistically significant.

\section{RESULTS}

The median age of patients with HAM/TSP was 54.0 years (range, $35-79$ years; $65.4 \%$ female) that of oligosymptomatic patients was 53 years (range, $37-82$; $60.9 \%$ female), which was greater than that of asymptomatic patients (38 years; range, $18-64$ years; $63.1 \%$ female).

The nucleotide at position -572 at IL- 6 promoter was non-polymorphic and only two heterozygote genotypes were found at -597 (one HAM/TSP patient and one healthy carrier); therefore subsequent association analysis was not carried out. In fact, previous studies have shown that these polymorphisms are rare in African and African-Amerindian populations (Cancer Genome Anatomy Project/SNP500Cancer Database accessed by http://snp500cancer.nci.nih.gov).

Table I show the IL-6 and IL-10 polymorphism frequencies in HTLV-1 infected and non-infected subjects. There was no difference between them for the three polymorphic sites analyzed at IL-6 and IL-10 promoter. Genotype frequencies from the three polymorphic sites $(-634 \mathrm{G} / \mathrm{C},-174 \mathrm{G} / \mathrm{C}$ IL6, and -592C/A IL10) did not differ significantly from those expected under the Hardy-Weinberg equilibrium.

The distribution of observed $-634 G / C,-174 G / C$ IL6, and $-592 C / A$ IL-10 allele frequencies among HTLV-1 infected patients according to the clinical status (asymptomatic, oligosymptomatic, and HAM/TSP) are shown in Tables II and III. Genotype frequencies did not differ significantly from those expected under the Hardy-Weinberg equilibrium. In relation to IL-6, there was no significant linkage disequilibrium between $-634 G / C$ and $-174 G / C$ polymorphisms $\left(\chi^{2}=0.525\right.$; $\mathrm{Df}=6 ; P=0.998)$. The $-634 C$ allele frequencies were higher among HAM/TSP patients (21.2\%) than among oligosymptomatic (6.5\%) and asymptomatic (9.5\%) patients. Similarly the $-174 \mathrm{G}$ allele frequencies were higher in HAM/TSP patients than in oligosymptomatic patients $(P=0.02)$, but the difference between HAM/ TSP and asymptomatic patients was not statistically significant $(P=0.12)$. The $-174 G$ allele, defined as "high" cytokine producer, was found in $94.2 \%, 78.3 \%$, and $86.3 \%$ of the HAM/TSP patients, oligosymptomatic, and asymptomatic patients, respectively. As regards IL-10, there was no association between the $-592 \mathrm{C} / \mathrm{A}$ IL-10 polymorphism and disease developing in HTLV-1 infected patients.

The analysis of the two-site IL-6 promoter genotype combination frequencies for the three clinical statuses among HTLV-1 infected subjects demonstrated that the wild genotype combination $(-634 G G /-174 G G)$ was more common in the three groups. The $-634 G C /$ $-174 G G$ genotype combination was at a higher frequency $(38.5 \%)$ in HAM/TSP patients than in subjects with other clinical status $(8.7 \% ; P=0.016$ for oligosymptomatic and $15.5 \%, P=0.012$ for asymptomatic), suggesting that this combination could be related to the development of HAM/TSP (data not shown). However, only the $-634 \mathrm{C}$ IL-6 carriers remain as significant and independent TSP/HAM predictor $(\mathrm{OR}=5.31 ; 95 \%$ $\mathrm{CI}=1.60-17.56 \% ; P=0.006)$, as shown by the multivariate logistic regression including the genotypes of the three studied loci (Table IV).

In addition, the $-634 G C$ genotype was related to an increased risk of developing HAM/TSP when this group was compared with asymptomatic patients (odds ratio $[\mathrm{OR}]=3.12 ; 95 \%$ confidence interval $[\mathrm{CI}]=1.07-8.86$; $P=0.021)$ and oligosymptomatic patients $([\mathrm{OR}]=4.89$; 95\% CI $=1.01-31.08 ; P=0.030)$. Given these OR we could estimate the prevented fraction (Fp) [Jeffery et al., 1999] for the development of HAM/TSP in HTLV-1

TABLE I. $-634 G / C$ and $-174 G / C$ IL-6 and $-592 C / A$ IL-10 in HTLV-1 Infected Individuals and Healthy Individuals

\begin{tabular}{|c|c|c|c|c|c|}
\hline & \multicolumn{3}{|c|}{ Genotypes } & \multicolumn{2}{|c|}{ Alleles } \\
\hline & $G G \mathrm{~N}(\%)$ & $G C \mathrm{~N}(\%)$ & $C C \mathrm{~N}(\%)$ & $G \mathrm{~N}(\%)$ & $C \mathrm{~N}(\%)$ \\
\hline \multicolumn{6}{|c|}{$\begin{array}{c}-634 G / C I L-6^{*} \\
\text { HTLV-1 }\end{array}$} \\
\hline+ & $103(77.4)$ & $30(22.6)$ & 0 & $236(88.7)$ & $30(11.3)$ \\
\hline- & $68(68.8)$ & $30(30.0)$ & $2(2.0)$ & $166(83.0)$ & $34(17.0)$ \\
\hline \multicolumn{6}{|c|}{$-174 G / C I L-6^{*}$} \\
\hline+ & $103(77.4)$ & $24(18.1)$ & $6(4.5)$ & $230(86.5)$ & 36 (13.5) \\
\hline- & $\begin{array}{c}71(71.0) \\
C C\end{array}$ & $\begin{array}{c}25(25.0) \\
C A\end{array}$ & $\begin{array}{c}4(4.0) \\
A A\end{array}$ & $\begin{array}{c}167(83.5) \\
C\end{array}$ & $\begin{array}{c}33(16.5) \\
A\end{array}$ \\
\hline \multicolumn{6}{|c|}{$-592 C / A$ IL-10* } \\
\hline+ & $41(36.6)$ & $48(42.85)$ & $23(20.55)$ & $130(58.0)$ & $94(42.0)$ \\
\hline- & $46(45.1)$ & $43(42.15)$ & $13(12.75)$ & $135(66.2)$ & 69 (33.8) \\
\hline
\end{tabular}

*A $P$-value was calculated by Fisher's exact test: $-174 G / C$ IL-6: $P=0.429$; OR: 1.26 ; 95\% CI: $0.73-2.18$; $-634 G$ / $C$ IL-6: $P=0.079$; OR: 0.62; 95\% CI: 0.35-1.09 and $-592 \mathrm{C} / \mathrm{A}$ IL-6: $P=0.091 ;$ OR: $1.41 ; 95 \% .14 \mathrm{CI}$ : $0.94-2$. 
TABLE II. IL-6 Promoter Polymorphism at Positions $-634 G / C$ and $-174 G / C$ in HTLV-1 Infected Oligosymptomatic, HAM/TSP Patients and Asymptomatic

\begin{tabular}{|c|c|c|c|c|c|}
\hline & \multicolumn{3}{|c|}{ Genotypes } & \multicolumn{2}{|c|}{ Alleles } \\
\hline & $G G \mathrm{~N}(\%)$ & $G C \mathrm{~N}(\%)$ & $C C \mathrm{~N}(\%)$ & $G \mathrm{~N}(\%)$ & $C \mathrm{~N}(\%)$ \\
\hline \multicolumn{6}{|l|}{-634 IL-6 } \\
\hline Asymptomatic (A) & $68(80.95)$ & $16(19.05)$ & 00 & $152(90.5)$ & $16(9.5)$ \\
\hline Oligosymptomatic $(\mathrm{O})$ & $20(87)$ & $03(13)$ & 00 & $43(93.5)$ & $03(6.5)$ \\
\hline $\mathrm{HAM} / \mathrm{TSP}(\mathrm{H})$ & $15(57.7)$ & $11(42.3)$ & - & $41(78.8)$ & $11(21.2)$ \\
\hline \multicolumn{6}{|l|}{-174 IL-6 } \\
\hline Asymptomatic & $65(77.4)$ & $15(17.8)$ & $04(4.8)$ & $145(86.3)$ & $23(13.7)$ \\
\hline Oligosymptomatic & $15(65.2)$ & $06(26.1)$ & $02(8.7)$ & $36(78.3)$ & $10(21.7)$ \\
\hline HAM/TSP & $23(88.5)$ & $3(11.5)$ & - & $49(94.2)$ & $03(5.8)$ \\
\hline
\end{tabular}

IL-6 allele frequencies (Fisher's exact test): $-634 G / C I L-6$ : A $\times$ O: $P=0.770$, OR: 1.51, 95\% CI: 0.4-8.44; $\mathrm{A} \times \mathrm{H}: P=0.032$, OR: $2.55,95 \%$ CI: $0.98-6.35$; $\mathrm{H} \times \mathrm{O}: P=0.046$, OR: $3.85,95 \%$ CI: $0.91-22.7 ;-174 G / C I L-$ 6: A $\times$ O: $P=0.247$, OR: $1.75,95 \%$ CI: $0.68-4.24 ; \mathrm{A} \times \mathrm{H}: P=0.146$, OR: $2.59,95 \%$ CI: $0.73-14.01 ; \mathrm{H} \times \mathrm{O}$ : $P=0.034$, OR: $4.54,95 \%$ CI: $1.05-27.07$.

infected subjects that carry the $-634 G G$ genotype. We estimated the HAM/TSP prevalence at $1 \%$ in HTLV-1 infected population similar to previous studies [Jeffery et al., 1999; Sabouri et al., 2004]. The Fp was $68 \pm 18 \%$ and $48.5 \pm 23 \%$ in relation to oligosymptomatic and asymptomatic subjects, respectively. This indicates that the $G G$ genotype prevents $\sim 68 \%$ of potential cases of HAM/TSP in oligosymptomatic patients and $\sim 48.5 \%$ in asymptomatic. To detect an $[\mathrm{OR}]=3$, in a sample of 84 versus 26 patients (asymptomatic vs. HAM/TSP), and considering the lowest genotype frequency as $20 \%$, the power of the study is roughly $50 \%$ to Fisher's exact test. In relation to allelic frequency, as we have the double, the power of the study is roughly $83 \%$.

\section{DISCUSSION}

In this work we have identified an association between $-634 C$ IL-6 variant and HAM/TSP unlike what was related before [Nishimura et al., 2002]. A previous study in Japan showed an association between the $-634 G$ IL-6 variant and the development of Human T-cell leukemia/lymphoma virus type 1 (HTLV-1) associated myelopathy [Nishimura et al., 2002]. This conflicting result could be due to ethnic's differences. In fact, few studies have investigated the $-634 C / G$ IL-6 gene polymorphism, and all had been carried out in Asian populations. Recently, we demon- strated a lower frequency of the -634 C IL- 6 allele among individuals from Salvador (a city with a high racial admixture and a main contribution from African ancestry) than that observed previously in Asians [Nishimura et al., 2002; Gadelha et al., 2005].

Moreover, in this study, the HAM/TSP patients presented the highest $-174 G$ allele frequency $(94.2 \%)$. The high IL-6 production could be involved in inflammatory aspects in HAM/TSP patients. In fact, high IL-6 levels have been demonstrated in several inflammatory diseases including rheumatoid arthritis, systemic lupus erithematosus, ankylosing spondylitis, Crohn's disease, and chronic inflammatory proliferative diseases [reviewed by Gabay et al., 2006; Ishihara and Hirano, 2002]. In addition, it has been demonstrated that the blockage of IL- 6 and IL- 6 signaling seems to be effective at prevention and treatment in inflammatory disease [reviewed by Gabay et al., 2006; Smolen and Maini, 2006]. IL-6 was also related with CNS injury in patients with the neuroinflammatory disorder transverse myelitis, resulting in demyelinization and axonal injury [Kaplin et al., 2005]. Besides, it was demonstrated, in the experimental autoimmune encephalomyelitis, that no inflammatory cells were observed in the central nervous system of IL-6 deficient mice, reinforcing the role of IL-6 in inflammatory disorders in the CNS [reviewed by Ishihara and Hirano, 2002]. In addition, the $-174 G / C$ IL-6 polymorphism has been studied extensively and is associated with many

TABLE III. IL-10 Promoter Polymorphism at Positions -592C/A in HTLV-1 Infected Oligosymptomatic, HAM/TSP Patients and Asymptomatic

\begin{tabular}{|c|c|c|c|c|c|}
\hline & \multicolumn{3}{|c|}{ Genotypes } & \multicolumn{2}{|c|}{ Alleles } \\
\hline & $C C \mathrm{~N}(\%)$ & $C A \mathrm{~N}(\%)$ & $A A \mathrm{~N}(\%)$ & $C \mathrm{~N}(\%)$ & $A \mathrm{~N}(\%)$ \\
\hline \multicolumn{6}{|l|}{-592 IL-10 } \\
\hline Asymptomatic & $31(42.5)$ & $29(39.7)$ & $13(17.8)$ & $91(62.3)$ & $55(37.7)$ \\
\hline Oligosymptomatic & $03(20.0)$ & $07(46.7)$ & $05(33.3)$ & $13(43.3)$ & $17(56.7)$ \\
\hline HAM/TSP & $07(29.2)$ & $12(50.0)$ & $05(20.8)$ & $26(54.2)$ & $22(45.8)$ \\
\hline
\end{tabular}

IL-10 allele frequencies (Fisher's exact test): $-592 \mathrm{C} / \mathrm{A} \mathrm{IL}-10: \mathrm{A} \times \mathrm{O}: P=0.067$, OR: 2.16, 95\% CI: 0.91-5.23; $\mathrm{A} \times \mathrm{H}: P=0.395$, OR: $1.40,95 \%$ CI: $0.68-2.85 ; \mathrm{O} \times \mathrm{A}: P=0.485$; OR: $1.55 ; 95 \%$ CI: $0.56-4.29$. 
TABLE IV. Multivariate Logistic Regression (HAM/TSP vs. Asymptomatic) Including the Three Analyzed Loci ( -634 $G \rightarrow C,-174 G \rightarrow C I L-6$, and $-592 A \rightarrow C I L-10)$

\begin{tabular}{lclc}
\hline & OR & \multicolumn{1}{c}{ IC 95\% } & $P$ \\
\hline IL-6 -634 CC+GC vs. $G G$ & 5.31 & $1.60-17.56$ & 0.006 \\
IL-6 - 174 GG vs. $G C+C C$ & 1.15 & $0.26-5.02$ & 0.849 \\
IL-10 -592 $A C+A A$ vs. $C C$ & 0.47 & $0.15-1.49$ & 0.200 \\
\hline
\end{tabular}

OR, odds ratio; CI, confidence interval.

disorders [Fishman et al., 1998; Jahromi et al., 2000; Jenny et al., 2002; Villuendas et al., 2002; Kubaszek et al., 2003; Licastro et al., 2003]. Furthermore, the $-174 G$ allele at IL-6 resulted in higher plasma IL-6 levels [Fishman et al., 1998]. Unexpectedly, no statistical difference between asymptomatic and HAM/ TSP individuals was found. In fact, the genetic susceptibility must be associated to polymorphisms combination or association.

In addition, the analysis of two-site IL-6 promoter genotype estimated frequencies in combination showed that the combination $-634 G C /-174 G G$ must be related to susceptibility to HAM/TSP development in our population. However, in the multivariate logistic regression analysis including the three loci, only $-634 C$ IL-6 allele carriers remain as a significant predictor of HAM/ TSP (OR: 5.3, IC $=1.6-17.6 ; P=0.006$ ), independently from the other two loci, showing that the most important effect should be related to $-643 G \rightarrow C$. Moreover, it was found that the $-634 \mathrm{C}$ allele in heterozygosity is related to the disease. As the $\mathrm{C}$ allele is not so frequent in our population, it was not possible to observe if the effect related to homozygosity could be higher.

We did not find any association between the $-592 \mathrm{~A}$ allele and the outcome of neurological disease in HTLV1 patients. Sabouri et al. [2004] have shown that the IL-10 -592A allele produced lower HTLV-1 Taxinduced activity and this allele was associated with lower susceptibility to HAM/TSP in individuals from Kagoshima/Japan. In fact, the genotype frequency of our population is different from that of the population analyzed by Sabouri et al. [2004] and this difference could also explain these results. Analyzing the $-592 \mathrm{~A}$ allele frequency in individuals from Salvador, we verified that the $-592 \mathrm{~A}$ allele frequency is lower in African descendents (data not shown).

HAM/TSP patients have higher proviral load levels than asymptomatic. However, the range of these levels is wide and overlapping and there is a consensus that the proviral load is not sufficient to cause the disease. Furukawa et al. [2003] suggested that the low production of inflammatory cytokines in asymptomatic HTLV1 carriers might contribute to maintain this status, and although a higher provirus load is relevant for the development of disease, other factors must be important. These individuals' differences might be due in part to polymorphism at cytokines genes. In fact, it has been demonstrated that cytokine gene polymor- phisms may affect protein production and lead to "high" or "low" cytokines production [Rosenwasser and Borish, 1997; Fishman et al., 1998]. Besides, these polymorphisms frequencies can differ in populations with different ethnic backgrounds [Cox et al., 2001; Meenagh et al., 2002; Gadelha et al., 2005].

In summary, our results demonstrated that the $G$ allele at -174 and $C$ allele at -634 could contribute to HAM/TSP development. The multivariate analysis showed that the $-634 \mathrm{C}$ allele seems to be the most important HAM/TSP predictor. In fact, we do not know if the individuals (oligosymptomatic or asymptomatic) will develop HAM/TSP. The disease is progressive, chronic, and its development is slow. Future fellowships are necessary to answer the question. It is very unlikely that single polymorphisms at cytokine genes explain the disease. However, the identification of the collective influence of several cytokine polymorphisms, their prevalence in the population, and their interaction could help us understanding the pathogenesis mechanisms.

\section{REFERENCES}

Abramson JH, Gahlinger PM. 2001. Computer program for epidemiologists: PEPI. Version 4.0. Salt Lake City, UT: Sagebrush Press.

Belluco C, Olivieri F, Bonafe M, Giovagnetti S, Mammano E, Scalerta R, Ambrosi A, Franceschi C, Nitti D, Lise M. 2003. -174 g >c polymorphism of interleukin-6 gene promoter affects interleukin-6 serum level in patients with colorectal cancer. Clin Cancer Res 9:2173-2176.

Cox ED, Hoffmann SC, DiMercurio BS, Wesley RA, Harlan DM, Kirk AD, Blair PJ. 2001. Cytokine polymorphic analyses indicate ethnic differences in the allelic distribution of interleukin-2 and interleukin-6. Transplantation 72:720-726.

Dourado I, Alcantara LC, Barreto ML, da Gloria Teixeira M, GalvaoCastro B. 2003. HTLV-1 in the general population of Salvador, Brazil: A city with African ethnic and socio-demographic characteristics. J Acquir Immune Defic Syndr 34:527-531.

Ershler WB, Keller ET. 2000. Age-associated increased interleukin-6 gene expression, late-life diseases, and frailty. Annu Rev Med 51:245-270.

Fishman D, Faulds G, Jeffery R, Mohamed-Ali V, Yudkin JS, Humphries S, Woo P. 1998. The effect of novel polymorphisms in the interleukin-6 (IL-6) gene on IL-6 transcription and plasma IL-6 levels, and an association with systemic-onset juvenile chronic arthritis. J Clin Invest 102:1369-1376.

Font J, Garcia-Carrasco M, Ramos-Casals M, Aldea AI, Cervera R, Ingelmo M, Vives J, Yague J. 2002. The role of interleukin-10 promoter polymorphisms in the clinical expression of primary Sjogren's syndrome. Rheumatology 41:1025-1030.

Furukawa Y, Saito M, Matsumoto W, Usuku K, Tanaka Y, Izumo S, Osame M. 2003. Different cytokine production in tax-expressing cells between patients with human $\mathrm{T}$ cell lymphotropic virus type I (HTLV-1)-associated myelopathy/tropical spastic paraparesis and asymptomatic HTLV-1 carriers. J Infect Dis 187:11161125.

Gabay C. 2006. Interleukin-6 and chronic inflammation. Arthritis Res Ther 8:S2-S3.

Gadelha SR, Alcantara LC, Costa GC, Rios DL, Galvao-Castro B. 2005 Ethnic differences in the distribution of interleukin-6 polymorphisms among three Brazilian ethnic groups. Hum Biol 77:509514 .

Galvao-Castro B, Loures L, Rodrigues LG, Sereno A, Ferreira-Junior OC, Franco LG, Muller M, Sampaio DA, Santana A, Passos LM, Proietti F. 1997. Distribution of human T-lymphotropic virus type 1 among blood donors: a nationwide Brazilian study. Transfusion $37: 242-243$

Gessain A, Barin F, Vernant JC, Gout O, Maurs L, Calender A, de Thé G. 1985. Antibodies to human T lymphotropic virus type-I in patients with tropical spastic paraparesis. Lancet 2:407-410. 
Hoffmann SC, Stanley EM, Cox ED, DiMercurio BS, Koziol DE, Harlan DM, Kirk AD, Blair PJ. 2002. Ethnicity greatly influences cytokine gene polymorphism distribution. Am J Transplant 2:560-567.

Ishihara K, Hirano T. 2002. IL-6 in autoimmune disease and chronic inflammatory proliferative disease. Cytokine Growth Factor Rev 13:357-368

Jahromi MM, Millward BA, Demaine AG. 2000. A polymorphism in the promoter region of the gene for interleukin-6 is associated with susceptibility to type 1 diabetes mellitus. J Interferon Cytokine Res $20: 885-888$.

Jeffery KJ, Usuku K, Hall SE, Matsumoto W, Taylor GP, Procter J, Bunce M, Ogg GS, Welsh KI, Weber JN, Lloyd AL, Nowak MA Nagai M, Kodama D, Izumo S, Osame M, Bangham CR. 1999. HLA alleles determine human T-lymphotropic virus-I (HTLV-1) proviral load and the risk of HTLV-1-associated myelopathy. Proc Natl Acad Sci USA 96:3848-3853.

Jenny N, Tracy RP, Ogg MS, Luong le A, Kuller LH, Arnold AM, Sharrett AR, Humphries SE. 2002. In the elderly, interleukin-6 plasma levels and the $-174 \mathrm{G}>\mathrm{C}$ polymorphism are associated with the development of cardiovascular disease. Arterioscler Thromb Vasc Biol 22:2066-2071.

Kitamura A, Hasegawa G, Obayashi H, Kamiuchi K, Ishii M, Yano M, Tanaka T, Yamaguchi M, Shigeta H, Ogata M, Nakamura N, Yoshikawa T. 2002. Interleukin-6 polymorphism $(-634 \mathrm{C} / \mathrm{G})$ in the promotor region and the progression of diabetic nephropathy in type 2 diabetes. Diabet Med 19:1000-1005.

Kodama D, Saito M, Matsumoto W, Sabouri AH, Izumo S, Arimura K, Usuku K, Bangham CR, Osame M. 2004. Longer dinucleotide repeat polymorphism in matrix metalloproteinase-9 (MMP-9) gene promoter which correlates with higher HTLV-1 Tax mediated transcriptional activity influences the risk of HTLV-1 associated myelopathy/tropical spastic paraparesis (HAM/TSP). J Neuroimmunol 156:188-194.

Kubaszek A, Pihlajamaki J, Punnonen K, Karhapaa P, Vauhkonen I, Laakso M, The C. 2003. -174G promoter polymorphism of the IL-6 gene affects energy expenditure and insulin sensitivity. Diabetes 52:558-561.

Li XH, Gaynor RB. 2000. Mechanisms of NF-kappaB activation by the HTLV type 1 tax protein. AIDS Res Hum Retroviruses 16:15831590.

Licastro F, Grimaldi LM, Bonafe M, Martina C, Olivieri F, Cavallone L, Giovanietti S, Masliah E, Franceschi C. 2003. Interleukin-6 gene alleles affect the risk of Alzheimer's disease and levels of the cytokine in blood and brain. Neurobiol Aging 24:921-926.

Ma W, Lim W, Gee K, Aucoin S, Nandan D, Kozlowski M, Diaz-Mitoma F, Kumar A. 2001. The p38 mitogen-activated kinase pathway regulates the human interleukin-10 promoter via the activation of Sp1 transcription factor in lipopolysaccharide-stimulated human macrophages. J Biol Chem 276:13664-13674.

Meenagh A, Williams F, Ross OA, Patterson C, Gorodezky C, Hammond M, Leheny WA. 2002. Middleton D frequency of cytokine polymorphisms in populations from Western Europe, Africa, Asia, the Middle East, and South America. Hum Immunol 63:1055.

Moore KW, de Waal Malefyt R, Coffman RL, O'Garra A. 2001. Interleukin-10 and the interleukin-10 receptor. Annu Rev Immunol 19:683-6765.

Mori N, Gill PS, Mougdil T, Murakami S, Eto S, Prager D. 1996 Interleukin-10 gene expression in adult T-cell leukemia. Blood 88:1035-1045.

Murphy EL, Hanchard B, Figueroa JP, Gibbs WN, Lofters WS, Campbell M, Goedert JJ, Blattner WA. 1989. Modelling the risk of adult T-cell leukemia/lymphoma in persons infected with human Tlymphotropic virus type I. Int J Cancer 43:250-253.

Nishimura M, Maeda M, Matsuoka M, Mine H, Saji H, Matsui M, Kuroda Y, Kawakami H, Uchiyama T. 2000. Tumor necrosis factor, tumor necrosis factor receptors type 1 and 2, lymphotoxin-alpha, and HLA-DRB1 gene polymorphisms in human T-cell lymphotropic virus type I associated myelopathy. Hum Immunol 61:12621269 .
Nishimura M, Matsuoka M, Maeda M, Mizuta I, Mita S, Uchino M, Matsui M, Kuroda Y, Kawakami H, Kaji R, Adachi A, Uchiyama T. 2002. Association between interleukin-6 gene polymorphism and human T-cell leukemia virus type I associated myelopathy. Hum Immunol 63:696-700.

Nobuhara Y, Usuku K, Saito M, Izumo S, Arimura K, Bangham CR, Osame M. 2006. Genetic variability in the extracellular matrix protein as a determinant of risk for developing HTLV-1-associated neurological disease. Immunogenetics 57:944-952.

Orland JR, Engstrom J, Fridey J, Sacher RA, Smith JW, Nass C, Garratty G, Newman B, Smith D, Wang B, Loughlin K, Murphy ED. 2003. Prevalence and clinical features of HTLV neurologic disease in the HTLV outcomes study. Neurology 61:1588-1594.

Osame MK, Usuku S, Izumo N, Ijichi H, Amitani A, Igata M, Matsumoto M, Tara M. 1986. HTLV-1 associated myelopathy, a new clinical entity. Lancet 1:1031-1032.

Plothow A, Benvenutti R, Contieri FL, Bicalho MG. 2003. Frequencies at three polymorphic sites of Interleukin-10 gene promoter in Brazilian renal recipients. Transplant Proc 35:2908-2910.

Poiesz BJ, Ruscetti FW, Mier JW, Woods AM, Gallo RC. 1980. T-cell lines established from human T-lymphocytic neoplasias by direct response to T-cell growth factor. Proc Natl Acad Sci USA 77:68156819 .

Rafatpanah H, Pravica V, Farid R, Abbaszadegan MR, Tabatabaei A, Goharjoo A, Etemadi MM, Hutchinson IV. 2004. Association of a novel single nucleotide polymorphism in the human perforin gene with the outcome of HTLV-1 infection in patients from northeast Iran (Mash-had). Hum Immunol 65:839-846.

Raymond M, Rousset F. 1995. GENEPOP (version 1.2): Population genetics software for exact tests and ecumenicism. J Hered 86:248249.

Rivera-Chavez FA, Peters-Hybki DL, Barber RC, O’Keefe GE. 2003. Interleukin-6 promoter haplotypes and interleukin-6 cytokine responses. Shock 20:218-223.

Rosenwasser LJ, Borish L. 1997. Genetics of atopy and asthma: The rationale behind promoter-based candidate gene studies (IL-4 and IL-10). Am J Respir Crit Care Med 156:S152-S155.

Sabouri AH, Saito M, Lloyd AL, Vine AM, Witkover AW, Furukawa Y, Izumo S, Arimura K, Marshall SE, Usuku K, Bangham CR, Osame M. 2004. Polymorphism in the interleukin-10 promoter affects both provirus load and the risk of human T lymphotropic virus type Iassociated myelopathy/tropical spastic paraparesis. J Infect Dis 190:1279-1285.

Saito M, Eiraku N, Usuku K, Nobuhara Y, Matsumoto W, Kodama D, Sabouri AH, Izumo S, Arimura K, Osame M. 2005. ApaI polymorphism of vitamin $\mathrm{D}$ receptor gene is associated with susceptibility to HTLV-1-associated myelopathy/tropical spastic paraparesis in HTLV-1 infected individuals. J Neurol Sci 232:2935 .

Shin HD, Winkler C, Stephens JC, Bream J, Young H, Goedert JJ, O'Brien TR, Vlahov D, Buchbinder S, Giorgi J, Rinaldo C, Donfield S, Willoughby A, O'Brien SJ, Smith MW. 2000. Genetic restriction of HIV-1 pathogenesis to AIDS by promoter alleles of IL10. Proc Natl Acad Sci USA 97:14467-14472.

Taylor A, Verhagen J, Blaser K, Akdis M, Akdis CA. 2006. Mechanisms of immune suppression by interleukin-10 and transforming growth factor-beta: The role of T regulatory cells. Immunology 117:433442.

Terry CF, Loukaci V, Green FR. 2000. Cooperative influence of genetic polymorphisms on interleukin-6 transcriptional regulation. J Biol Chem 275:18138-18144

Warle MC, Farhan A, Metselaar HJ, Hop WC, Perrey C, Zondervan PE, Kap M, Kwekkeboom J, Ijzermans JN, Tilanus HW, Pravica V, Hutchinson IV, Bouma GJ. 2003. Are cytokine gene polymorphisms related to in vitro cytokine production profiles? Liver Transpl 9:170-181.

Westendorp RG, Langermans JA, Huizinga TW, Verweij CL, Sturk A. 1997. Genetic influence on cytokine production in meningococcal disease. Lancet 349:1912-1913. 